\title{
Epinephrine soaked tampons induced transient acute dilated cardiomyopathy during FESS procedure
}

\author{
Sari Naddaf', Scott Ehrenberg ${ }^{1}$, Rony Hakim², Muhamad Mahamid ${ }^{3}$, Yoav Turgeman ${ }^{1,3}$ and Ofir Koren ${ }^{1,3^{*}}$ (D
}

\begin{abstract}
Background: Epinephrine, in all modes of use, may pose a wide range of cardiotoxic events, ranging from sinus tachycardia to heart failure, life threatening arrhythmias, and even death. Because of daily and extensive use of epinephrine, these unusual and rare events tend to be forgotten by physicians. We present a case of dilated cardiomyopathy that developed following routine use of epinephrine-impregnated tampons during function endoscopic sinus (FESS) surgery.

Case presentation: A healthy, 24-year-old man with no family history of heart disease has undergone elective surgery under general anesthesia to repair the paranasal sinuses using endoscopic approach. During surgery, soon after being treated with 1: 1000 diluted epinephrine-soaked tampons, an hypertensive crisis was noticed followed by pulseless electrical activity. An extensive examination led to the diagnosis of non-ischemic dilated cardiomyopathy. After several days of heart failure medical therapy, complete resolution of all structural and functional changes was achieved.
\end{abstract}

Conclusion: In our case, we present an unusual and rare event of acute dilated cardiomyopathy following the use of epinephrine-soaked tampons during elective FESS surgery. A prompt response was observed after several days of heart failure treatment. Awareness of the epinephrine cardiotoxic potential even in the form of soaked tampons is essential for proper diagnosis and prompt treatment.

Keywords: Epinephrine, Dilated cardiomyopathy, Heart failure, FESS, Surgery

\section{Background}

Dilated cardiomyopathy (DCM) is recognized by the dilation of the right, left, or both ventricles in the absence of abnormal loading conditions as hypertension and valve disease, or significant coronary artery disease [1-5].

The etiology of DCM is extremely heterogeneous sometimes classified based on known genetic mutation. Among the non-genetics cause are different etiologies,

\footnotetext{
* Correspondence: Drkorenofir@gmail.com

'Bruce Rappaport Faculty of Medicine, Technion-Israel Institute of Technology, Haifa, Israel

${ }^{3}$ Heart Institute, Emek Medical Center, Afula, Israel

Full list of author information is available at the end of the article
}

including myocarditis, exposure to drugs as cocaine, certain toxins as alcohol or allergens; complication of pregnancy, systemic endocrine or autoimmune diseases, and infection as HIV [6].

One of the rarest etiologies regarding toxin and metabolic-related cause of DCM is catecholamines, and its various derivates, which has been reported mainly in case reports or short series review [7-13].

Pheochromocytoma, as a rare neuroendocrine catecholamine-producing tumor, has also been described as an etiology of reversible DCM and was found in $39 \%$ of pheochromocytoma-related cardiomyopathies [14]. Paul et al. proposed that catecholamine-induced vasoconstriction, a direct toxic effect of the by-products

(c) The Author(s). 2020 Open Access This article is licensed under a Creative Commons Attribution 4.0 International License, which permits use, sharing, adaptation, distribution and reproduction in any medium or format, as long as you give appropriate credit to the original author(s) and the source, provide a link to the Creative Commons licence, and indicate if changes were made. The images or other third party material in this article are included in the article's Creative Commons licence, unless indicated otherwise in a credit line to the material. If material is not included in the article's Creative Commons licence and your intended use is not permitted by statutory regulation or exceeds the permitted use, you will need to obtain permission directly from the copyright holder. To view a copy of this licence, visit http://creativecommons.org/licenses/by/4.0/ The Creative Commons Public Domain Dedication waiver (http://creativecommons.org/publicdomain/zero/1.0/) applies to the data made available in this article, unless otherwise stated in a credit line to the data. 
of catecholamine degradation and direct receptormediated mechanisms, contribute to cardiomyopathy in subjects with pheochromocytoma [15].

\section{Case description}

A 24-year old male with chronic rhinosinusitis was admitted for an elective Functional endoscopic sinus surgery (FESS) procedure under general anesthesia. During the operation, the surgeon applied several tampons soaked in 1:1000 dilution epinephrine to the nasal mucosa. Ninety minutes into the surgery, unexpectedly, blood pressure rose to $210 / 130 \mathrm{mmHg}$ followed by pulseless electrical activity. CPR was initiated, with the administration of $2 \mathrm{mg}$ of IV epinephrine in consecutive doses, leading to the return of spontaneous circulation. ECG showed sinus tachycardia and a prolonged QTc interval of $486 \mathrm{~ms}$, Inverted T waves in leads I and aVL, and no signs of acute ischemic changes (Fig. 1). A chest $\mathrm{x}$-ray demonstrated pulmonary edema and a borderline enlarged cardiac silhouette (Fig. 2).

The patient was placed on mechanical ventilation. Transthoracic echocardiogram showed a dilated left ventricle with an increased end-diastolic dimension (124\% of normal value) with a mild reduction in LV mass, a severe reduction in systolic function, apical akinesis, and hyperdynamic base. The estimated systolic left ventricular ejection fraction was $30 \%$ (Fig. 3). Cardiac troponin and CPK were elevated. NT or NT pro-BNP were not taken. A head CT was performed and demonstrated mild global cerebral edema, with multiple maxillary sinus fractures (Fig. 4).

Medical information gathered from family members indicated no family history of heart diseases. The patient did not smoke, use illegal drugs nor consumed alcohol on daily basis. The patient was diagnosed with dilated cardiomyopathy and admitted to the intensive cardiac care unit. Upon arrival, upload

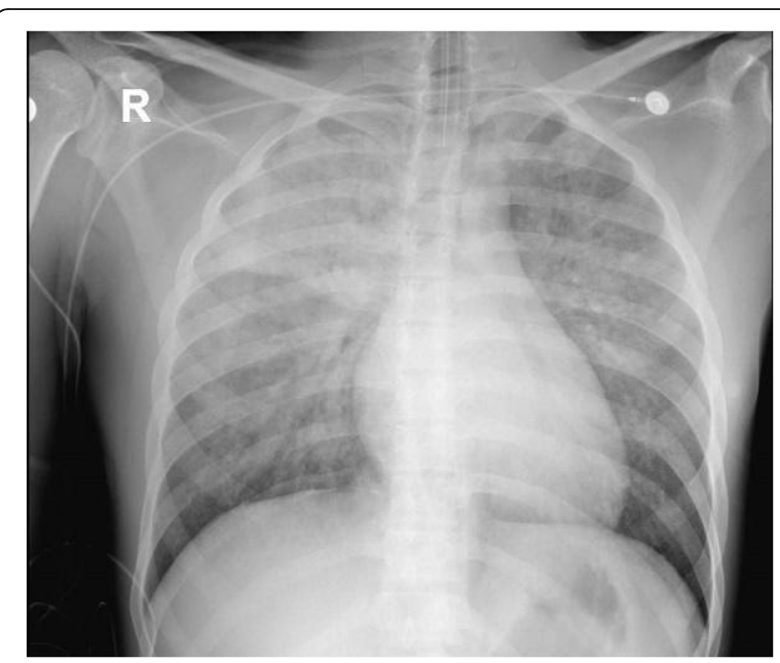

Fig. 2 Chest $X$-ray at admission indicate bilateral pulmonary edema and normal heart silhouette

titration of ACE inhibitors, $\beta$-blockers, and diuretics initiated. The following ECG strips indicate normal sinus rhythm, QTc interval of $420 \mathrm{~ms}$, and normal T wave in lateral leads. We decided not to perform a diagnostic coronary catheterization since the patient's risk profile for ischemic cardiomyopathy was low. Objectively, there were no ischemic changes on ECGs strips and no regional wall motional abnormalities were seen on TTE upon arrival.

Three days later, a second echocardiogram was performed which showed a normal-sized left ventricle, with preserved systolic function (Fig. 5).

The patient was discharged in full functional capacity. An ambulatory cardiac MRI performed two weeks after discharge revealed mildly dilated LV cavity, good global systolic function, and no signs of late gadolinium enhancement or edema.

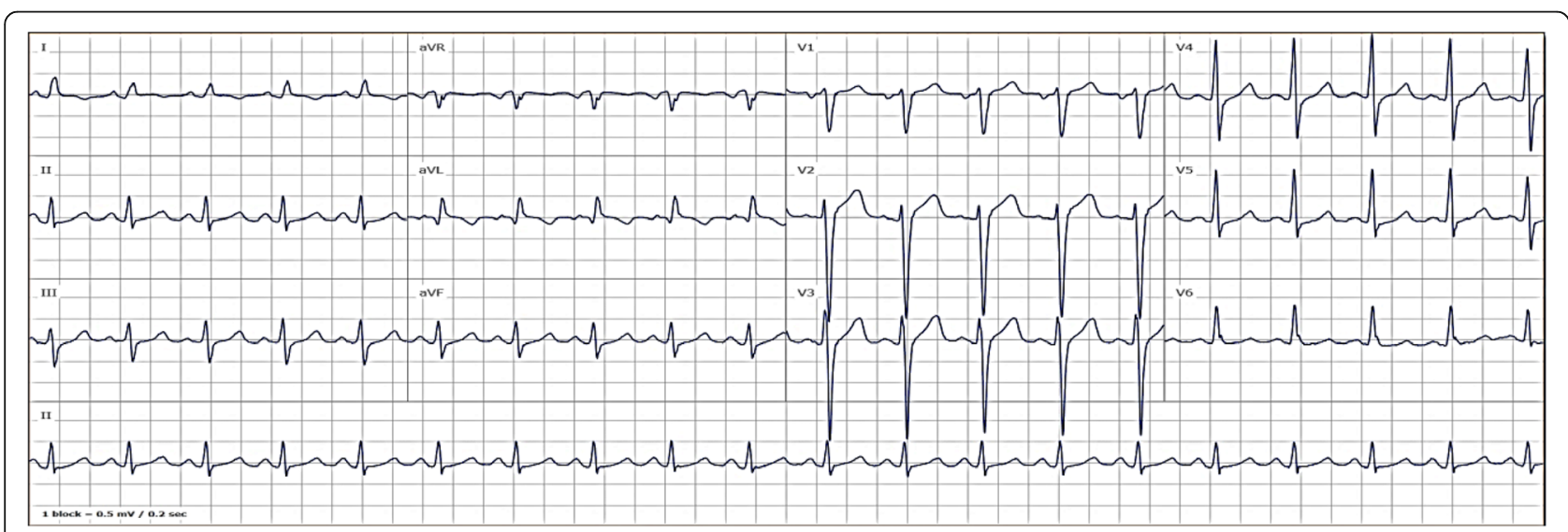

Fig. 1 ECG at admission indicate sinus tachycardia, prolonged QTc (QTC $=486 \mathrm{~ms})$, Inverted T waves in leads I and aVL, and no signs of acute Ischemic changes 


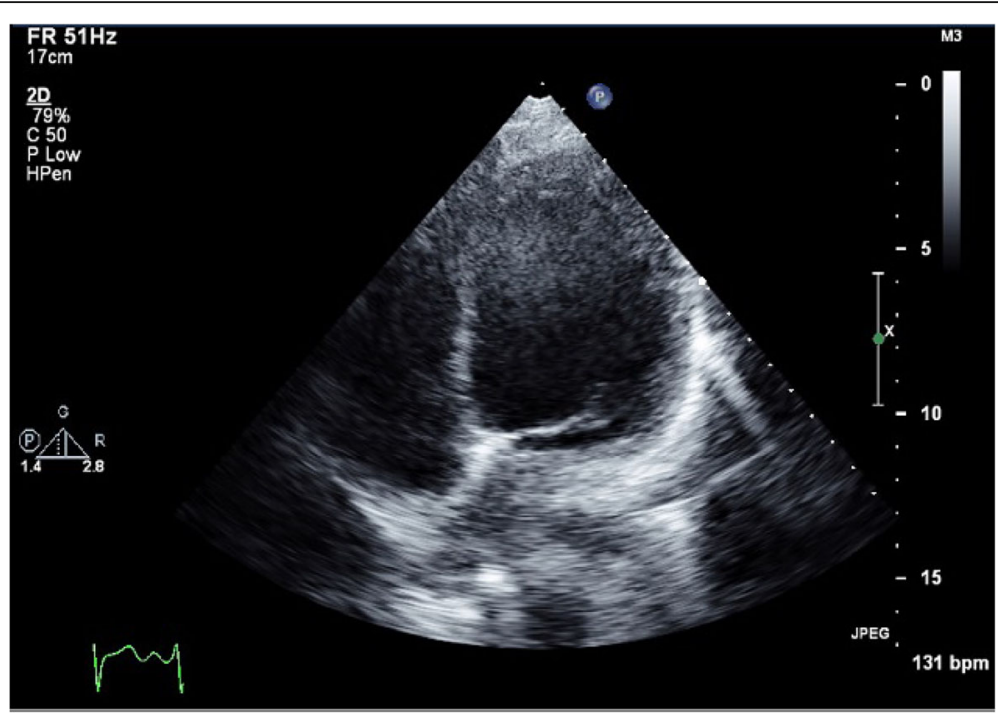

Fig. 3 Transthoracic Echocardiography at admission demonstrates a dilated left ventricle dimension. Apical 4 Chambers view at the end of the diastole

\section{Discussion}

The relationship between exogenous catecholamines and dilated cardiomyopathy is not fully understood. Some propose that elevated catecholamine levels decrease myocardial viability via cyclic - AMP mediated $\mathrm{Ca}+$ overload $[16,17]$.

While reductions in ejection fraction and left ventricular dysfunction was found to be reversible, mild histologic changes were found in dog studies indicate chronic perivascular fibrosis which seems to be irreversible [18].

Since activation of alpha or adrenergic receptors has been shown to induce stress-induced cardiomyopathy, it has been shown in studies that these cardiac effects can be attenuated by pretreatment with the use of alpha and beta blockers [19-23]. In addition, increasing levels of estrogen have shown partial attenuation of these cardiac changes [24, 25].

Dilated cardiomyopathy is usually characterized by long-standing processes or conditions, its appearance in the acute setting is not common and a detailed evaluation of acute onset dilated cardiomyopathy (ADCM) typically does not elucidate a specific etiology in most cases [26].

\section{Conclusion}

We report a rare case of a transient acute non-ischemic transient dilated cardiomyopathy following exposure to sstandard diluted dose epinephrine soaked-tampons during ENT procedure. Prompt heart failure treatment resulted in complete resolution. Our report provides
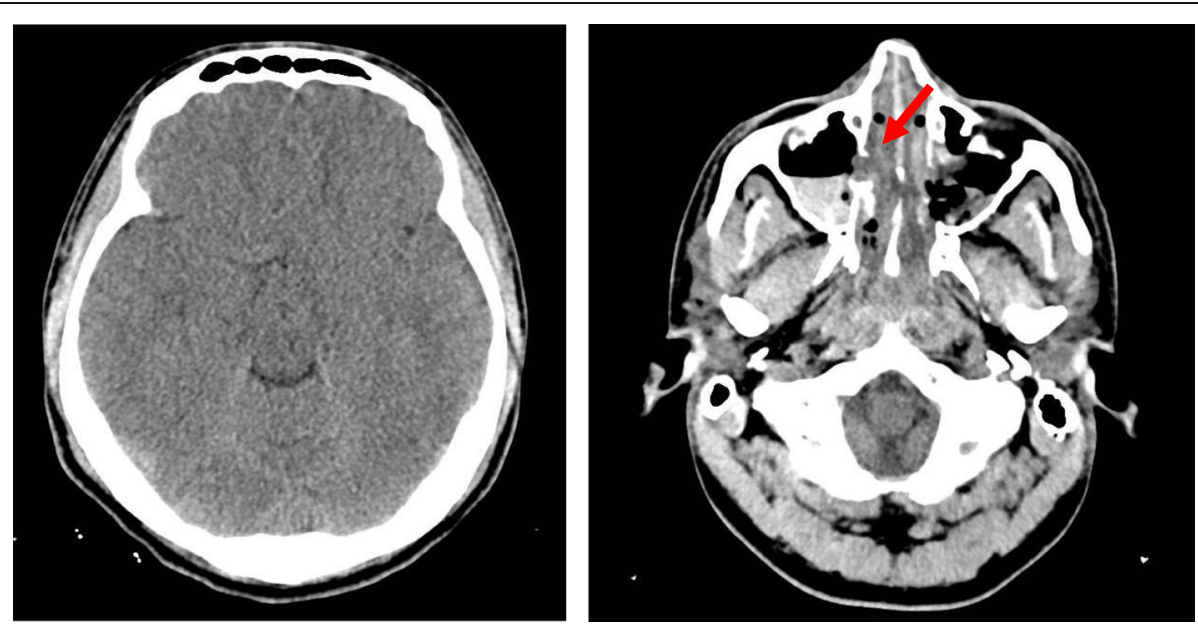

Fig. 4 Head CT at admission shown Global Edema (Left-sided) and multiple Maxillary Sinuses fractures (Right-sided red arrow) 


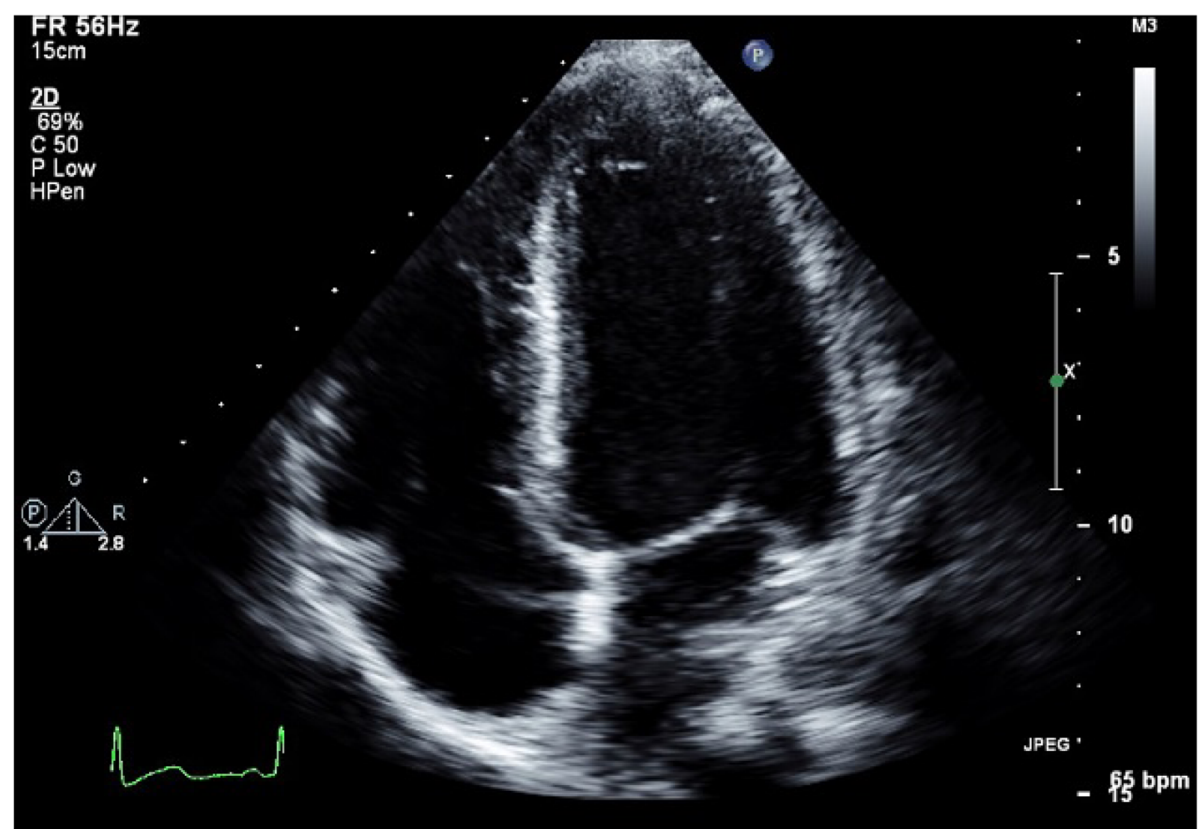

Fig. 5 Transthoracic Echocardiography at discharge demonstrates a normal-sized left ventricle dimension with normal LV mass. Apical 4 Chambers view at the end of the diastole

supporting evidence of the cardiotoxic devastating potential effect of epinephrine and its role in acute dilated cardiomyopathy. We hope that this paper will raise awareness among physicians and surgeons to the relevance of cardiotoxic effect of epinephrine, especially in the form of soaked tampons.

\section{Abbreviations}

FESS: Functional endoscopic sinus surgery; ENT: Ear, nose and throat; DCM: Dilated cardiomyopathy; ECG: Electrocardiography; TTE: Transthoracic echocardiography; CT: Computerized tomography; MRI: Magnetic resonance imaging; PEA: Pulseless electrical activity; CPR: Cardiopulmonary resuscitation; ACEl: Angiotensin-converting enzyme inhibitor; BB: Beta-blocker

\section{Acknowledgments}

n/a

\section{Authors' contributions}

$\mathrm{SN}, \mathrm{SE}, \mathrm{RH}, \mathrm{MM}$, and OK contributed to the writing, editing, formatting of the main manuscript, and production of the Figs. MM, OK and YT provided care to the patient and revised the manuscript. All authors have read and approved the manuscript.

\section{Funding}

The authors have not declared a specific grant for this research from any funding agency in the public, commercial, or not-for-profit sectors.

\section{Availability of data and materials}

The datasets used and/or analyzed during the current study are available from the corresponding author on reasonable request.

\section{Ethics approval and consent to participate}

Informed consent was waived due to the use of anonymous patient's data as well as due to the retrospective nature of the case study.

\section{Consent for publication}

Written consent to publish the information presented in the clinical case was obtained from the patient.

\section{Competing interests}

The authors declare that they have no competing interests.

\section{Author details}

'Bruce Rappaport Faculty of Medicine, Technion-Israel Institute of Technology, Haifa, Israel. ${ }^{2}$ Department of Anaesthesia, Emek Medical Center, Afula, Israel. ${ }^{3}$ Heart Institute, Emek Medical Center, Afula, Israel.

Received: 5 June 2020 Accepted: 16 September 2020

Published online: 16 October 2020

\section{References}

1. Dec GW, Fuster V. Idiopathic dilated cardiomyopathy. N Engl J Med. 1994; 331(23):1564-75.

2. Elliott P. Diagnosis and management of dilated cardiomyopathy. Heart. 2000;84(1):106-12.

3. Towbin JA, Bowles NE. Dilated cardiomyopathy: a tale of cytoskeletal proteins and beyond. J Cardiovasc Electrophysiol. 2006;17(8):919-26.

4. Lakdawala NK, Winterfield JR, Funke BH. Dilated cardiomyopathy. Circulation. 2013;6:228-37.

5. Oakley CM. Report of the WHO/ISFC task force on the definition and classification of cardiomyopathies. Br Heart J. 1980;44(6):672-3.

6. Schultheiss H, Fairweather D, Caforio ALP, et al. Dilated cardiomyopathy. Nat Rev Dis Primers. 2019;5:32. https://doi.org/10.1038/s41572-019-0084-1.

7. Paur H, Wright PT, Sikkel MB, et al. High levels of circulating epinephrine trigger apical cardiodepression in a $\beta 2$-adrenergic receptor/Gi-dependent manner: a new model of Takotsubo cardiomyopathy. Circulation. 2012; 126(6):697-706. https://doi.org/10.1161/CIRCULATIONAHA.112.111591.

8. Rona G. Catecholamine cardiotoxicity. J Mol Cell Cardiol. 1985;17(4):291-306.

9. Litvinov IV, Kotowycz MA, Wassmann S. latrogenic epinephrine-induced reverse Takotsubo cardiomyopathy: direct evidence supporting the role of catecholamines in the pathophysiology of the "broken heart syndrome". Clin Res Cardiol. 2009:98:457-62 https://doi-org.ezlibrary.technion.ac.il/10.1 007/s00392-009-0028-y.

10. Lyon AR, Rees PS, Prasad S, Poole-Wilson PA, Harding SE. Stress (Takotsubo) cardiomyopathy--a novel pathophysiological hypothesis to explain catecholamine-induced acute myocardial stunning. Nat Clin Pract Cardiovasc Med. 2008;5(1):22-9. https://doi.org/10.1038/ncpcardio1066. 
11. Stewart MJ, Fraser DM, Boon N. Dilated cardiomyopathy associated with chronic overuse of an adrenaline inhaler. Heart. 1992;68(8):221-2.

12. Szakacs JE, Cannon A. L-norepinephrine myocarditis. Am J Clin Pathol. 1958; 30(5):425-34. https://doi.org/10.1093/ajcp/30.5.425.

13. Zhang R, Gupta D, Albert SG. Pheochromocytoma as a reversible cause of cardiomyopathy: analysis and review of the literature. Int J Cardiol. 2017;249: 319-23.

14. Paul T, Varghese R, John A. Catecholamine induced cardiomyopathy in pheochromocytoma. Indian J Endocrinol Metab. 2013;17(4):733.

15. Wittstein IS, Thiemann DR, Lima JA, et al. Neurohumoral features of myocardial stunning due to sudden emotional stress. N Engl J Med. 2005; 352(6):539-48. https://doi.org/10.1056/NEJMoa043046.

16. Spina R, Song N, Kathir K, Muller DWM, Baron D. Takotsubo cardiomyopathy following unintentionally large subcutaneous adrenaline injection: a case report. Eur Heart J Case Rep. 2018;2(2):yty043. Published 2018 Apr 18. https://doi.org/10.1093/ehjcr/yty043.

17. Hens L, Dambrink JH. Alcohol and drugs: twins or evil in a young heart. Acta Cardiol. 2012;67:469-71.

18. Movahed A, Reeves WC, Mehta PM, Gilliland MGF, Mozingo SL, Jolly SR. Norepinephrine-induced left ventricular dysfunction in anesthetized and conscious, sedated dogs. Int J Cardiol. 1994;45(1):23-33.

19. Mizia-Stec K, Gasior Z, Wojnicz R, et al. Severe dilated cardiomyopathy as a consequence of ecstasy intake. Cardiovasc Pathol. 2008;17(4):250-3.

20. Dorn GW II. Apoptotic and non-apoptotic programmed cardiomyocyte death in ventricular remodeling. Cardiovasc Res. 2009;81(3):465-73.

21. Barison A, Masci PG, Emdin M. Fibrosis and mortality in patients with dilated cardiomyopathy. J Am Med Assoc. 2013;309(24):2547-9.

22. Zhong L, Ghista DN, Tan RS. Left ventricular wall stress compendium. Comput Methods Biomechanics Biomed Eng. 2012;15(10):1015-41.

23. Goldstein S, Ali AS, Sabbah H. Ventricular remodeling: mechanisms and prevention. Cardiol Clin. 1998;16(4):623-32.

24. Pahl E, Sleeper LA, Canter CE, et al. Incidence of and risk factors for sudden cardiac death in children with dilated cardiomyopathy: a report from the pediatric cardiomyopathy registry. J Am Coll Cardiol. 2012;59(6):607-15.

25. Okutucu S, Oto A. Risk stratification in nonischemic dilated cardiomyopathy: current perspectives. Cardiol J. 2010;17(3):219-29.

26. Felker M, Thompson RE, Hare JM, et al. Underlying causes and long-term survival in patients with initially unexplained cardiomyopathy. N Engl J Med. 2000:342:1077-84

\section{Publisher's Note}

Springer Nature remains neutral with regard to jurisdictional claims in published maps and institutional affiliations.

Ready to submit your research? Choose BMC and benefit from:

- fast, convenient online submission

- thorough peer review by experienced researchers in your field

- rapid publication on acceptance

- support for research data, including large and complex data types

- gold Open Access which fosters wider collaboration and increased citations

- maximum visibility for your research: over $100 \mathrm{M}$ website views per year

At $\mathrm{BMC}$, research is always in progress.

Learn more biomedcentral.com/submissions 